ORIGINAL ARTICLE

\title{
Playing traditional games vs. free-play during physical education lesson to improve physical activity: a comparison study
}

\author{
'Arif Azlan ${ }^{\mathrm{ABCD}}$, Nadzirah Ismail ${ }^{\mathrm{ABCD}}$, Nor Farah Mohamad Fauzi ${ }^{\mathrm{ACDE}}$, Ruzita Abd. Talib ${ }^{\mathrm{ACDE}}$
}

National University of Malaysia, Malaysia

Authors' Contribution: A - Study design; B - Data collection; C - Statistical analysis; D - Manuscript Preparation; E - Funds Collection.

\begin{abstract}
Purpose: $\quad$ Non-sport activities like traditional games can be a practical way to promote physical activity (PA) during physical education (PE) lessons, especially among those who are less inclined towards sports. The purpose of this study is to compare the PA variables and acceptance between playing traditional games and free-play during physical education lessons among secondary school students.

Material: $\quad$ Fifty-six $(n=56)$ subjects participated in this study wore accelerometers for a total of 40 minutes during each PE lesson to record PA. In the first week, a 40-min free-play PE lesson was done while in the second week, a 40-min PE lesson incorporated with traditional games (TG-PE lesson) was done. After following both lessons, subjects filled up a questionnaire on acceptance of TG-PE and free-play PE lessons.

Results: $\quad$ The mean total activity count $(p<0.05)$ and time spent in moderate-to-vigorous physical activity (MVPA) $(p<0.05)$ were $20 \%$ and $19 \%$ greater respectively during TG-PE lesson compared to free-play PE lesson. The mean acceptance scores showed students preferred playing TG $(19.29 \pm 4.21 ; p<0.00)$ over free-play PE lesson (17.59 \pm 3.13$)$.

Conclusions: In conclusion, incorporating fun and meaningful activities such as TG during PE lessons can serve as an alternative strategy to promote PA during school hours. Further studies are warranted to determine other types of TG that may promote PA among secondary school students.

Keywords: $\quad$ adolescents, exercise, physical activity, physical education, traditional games
\end{abstract}

\section{Introduction}

Physical activity (PA) is an essential contributing factor to children's and adolescents' well-being [1]. However, according to the Active Healthy Kids Global Alliance report from 49 countries, children around the world were not getting enough PAs, consequent to urbanisation and technological advancement [2]. The Malaysian School-Based Nutrition Survey (MSNS) reported that $50 \%$ of Malaysian school children aged 10 to 17 years were physically inactive, with girls being less active compared to boys [3]. In 2017, Institute of Public Health, Malaysia reported only $20 \%$ of secondary school children met the PA recommendations for children and adolescents (60 minutes of moderate-to-vigorous physical activity [MVPA]) [4]. The lack of activities has major implications for the health of children, and may be responsible for the rising paediatric obesity pandemic. Reducing physical inactivity would certainly reduce the risk of non-communicable diseases during childhood, as well as when they reach adulthood [5].

Physical education (PE) lessons in school provides an excellent avenue for children and adolescents to be physically active during school hours [6]. A high-quality PE curriculum enables all students to enjoy different types of PA, apart from having many positive benefits to physical and mental health such as improving cardiorespiratory fitness and body composition [7], increasing cognitive and academic performance $[8,9]$, and reducing mental

\footnotetext{
(c) 'Arif Azlan, Nadzirah Ismail, Nor Farah Mohamad Fauzi,

Ruzita Abd. Talib, 2021

doi:10.15561/26649837.2021.0306
}

stress among school children [10]. A study by Chen, Kim [11] indicated that school children who had greater frequency of participation in PE lessons were more likely to spend greater time in MVPA, even after school hours. Silva, Chaput [12] reported that an average of two times per week of PE lessons is needed to achieve an overall improvement on PA. PE is a compulsory subject taught in Malaysian primary and secondary schools and is divided into two parts: physical education (taught outside classroom) and health education (assigned topics taught in classroom) [13]. However, PE has become a lessfavoured subject in recent years and is often viewed as a marginal subject within the curriculum, especially among secondary school students $[14,15]$. Apart from a well-designed PE curriculum, the effectiveness of PE lesson delivery relies heavily on the teacher's competency and enthusiasm to motivate students to participate in PAs [16]. It is common to find non-specialised teachers teaching PE in schools and this contributes significantly to the PE quality [17]. Rustam and Kassim [18] reported a high incidence of lack of observation and supervision of PE lessons by school administrators in Malaysian schools, leading to inconsistencies as to how PE lessons are conducted across many schools [13]. Apart from the personnel factor, some studies reported that other factors impeding students' participation in PE lessons are lack of sports equipment and facilities [19-21].

Perhaps the most sustainable and quickest approach to promote PA during PE lessons among school children is to incorporate fun and meaningful activities [22] that 
will appeal to not only sports-inclined students, but also those who regard themselves as 'less sporty' [23]. One example is playing traditional games. Traditional games (TG) are simple in design and implementation, suitable in all weather conditions with low cost, space, time, and equipment, but still capable of promoting PA, comparable to playing organised sports [24, 25]. Enjoyment factor in TG can be an excellent way to motivate less physically active students to be active during PE lessons, something which organised sports cannot do [26]. Malaysia is a country rich with cultural heritage, especially TG. Among the various types of TG played in Malaysia are Gasing (Spintop), Batu Seremban (Five Stones), Teng-Teng (Hopscotch), Polis Sentri (Police and Thief), Baling Selipar (Throwing Slipper), Galah Panjang (Long Pole), and Konda Kondi (Catch the Stick) [27]. TG in Malaysia were formerly popular and played by people from a wide range of age and race. However, its popularity has dwindled over the last few decades and is less played by today's younger generation [28]. UNESCO encourages promotion of TG in order to foster cultural identities and respect for communities from different cultural background [25, 29].

Re-introducing TG into PE lessons would not only encourage the younger generation to appreciate Malaysian heritage and culture, but also be an alternative strategy to promote PA and health-related fitness among school children [25]. A recent intervention study in Iran demonstrated a positive effect of PE and TG in reducing overweight problem among secondary school girls [30]. Other studies reported that playing TG improves motor-related fitness such as agility, speed, and balance among primary and secondary school students [28, 31]. However, the levels of MVPA engaged while playing games were not assessed in previous studies, especially among secondary school children. Furthermore, it is not currently known whether playing TG during PE lessons would lead to a higher PA level compared to free-play, unstructured PE lessons normally taught in schools.

Despite the benefits of TG in terms of health and fitness, its acceptance among children and adolescents is still obscure. There are so many reasons why playing TG is being overlooked. One of the reasons is the emergence of technological gadgets. Today, children and adolescents prefer to stay inside the house and play with their gadgets, instead of playing outside [32]. Due to safety reasons, parents also discourage their children to play outside in the neighbourhood [33]. A study in the Philippines reported that half of the children feel safer playing computer games instead of playing physically outside their house [34]. In terms of the excitement of playing TG, a previous study reported that $78 \%$ of adolescents in Pakistan were not interested in playing traditional games [35]. Mohd Yusoff [36] explained that today's younger generation feel playing TG is boring, outdated, and unsuitable with modern times. In addition, most of the previous studies done on primary school students only showed an increase of self-efficacy level after playing TG $[26,37,38]$. Their acceptance level after playing TG, such as enjoyment, satisfaction, suitability, and future participation was not shown. No published data was confirmed regarding acceptance towards playing TG among secondary school students.

We hypothesised higher PA variables towards active TG during a PE lesson than a free-play PE lesson among secondary school students. We also hypothesised that active TG during a PE lesson will yield high acceptance score than a free-play PE lesson among secondary school students. The primary aim of this study is to determine and compare PA variables of playing TG and free-play during PE lessons. The secondary aim is to determine and compare acceptance scores between playing TG during a PE lesson and a free-play PE lesson among secondary school students. Further attention was focused on the difference of PA levels and acceptance scores between genders.

\section{Material and Methods}

Participants.

A list of secondary schools in Kuala Lumpur was obtained from the Kuala Lumpur Federal Territory Education Department. Purposive sampling method was adopted to select a secondary school from the list. The inclusion criteria for the school were co-ed Malaysian secondary school. While inclusion criteria for the student were aged between 13 and 14 or studying in the Form 1 and Form 2 classes. Finally, one secondary school from the Keramat district was chosen for the study. Subjects were excluded if they had chronic medical conditions or physical disabilities that would limit movement. The minimum sample size was calculated with GPower software [39] based on a previous study by Wilson, Evans [40] where the minimum sample was 36 subject.

\section{Research Design}

This study design was a cross-sectional study. Approval to conduct the study was obtained from the National University of Malaysia Research Ethics Committee (UKM1.21.3/ 244/ NN-2018-130) and the Ministry of Education (KPM.600-3/2/3-eras(1151)). Subjects were briefed about the study and informed that they have the right to refuse to participate if they wish to do so. Parental informed consent and student consent were obtained prior to data collection.

Subjects underwent anthropometric measurements prior to the study. Height and weight were measured using a SECA portable stadiometer 213 (SECA, German) and a digital weighing scale Model 803 (SECA, German), respectively. Body mass index (BMI) was calculated and the categories were determined according to z-score for BMI-for-age as previously set by WHO [41]. Waist circumference was measured using Lufkin W606PM (Lufkin, USA), while Omron Body Fat Analyser HBF306 (Omron, Japan) was used to measure students' body fat percentage. Waist circumference was used to classify abdominal obesity based on Poh, Jannah [42].

The study was conducted in two PE lessons across two weeks. In the first week, subjects followed a freeplay 40-min PE lesson, during which subjects had 
the freedom to carry out their preferred PA under a PE teacher's supervision. In the second week, subjects followed a 40-min PE lesson integrated with traditional games (TG-PE lesson). Due to the limitation of school compound, subjects played TG in the school hall. Each game was played for 20 minutes in multiple groups. All activities during TG-PE lesson were monitored by the researchers and PE teacher. Upon completion of both PE periods, subjects were asked to fill out a questionnaire on acceptance of playing TG and PE lesson activities.

Two traditional games (TG) were selected for this study, Galah Panjang (Long Pole) and Baling Selipar (Throwing Slipper). The selection of the games was based on the intensity and involvement of running activity [28]. Galah Panjang is a game which involves two teams, where one team is required to run past several parallel lines, guarded by the opposing team, without being touched or tagged by the opposing team [43]. Baling Selipar also involves two teams, the 'attack' and 'defend' teams. It is a strategic game, revolving around the mechanism of 'build-destroy-rebuild a pyramid'. The defending team is required to build a pyramid on the ground, using three rubber slippers. The attacking team's mission is to knock down the pyramid by throwing a slipper. The defending team needs to prevent the attacking team from rebuilding the pyramid arrangement by flinging a slipper to oust the attacking team [25].

PA was measured using Actigraph GT3X+ (Pensacola, Florida, USA). Subjects were instructed to wear the accelerometer attached to an elasticised belt around the waist, positioned just above the right hip during PE lessons. The data was downloaded using Actilife software version 6.13.2. The levels of PA were evaluated as total activity count, time spent in MVPA based on Freedson cut-off point [44], time spent in sedentary activity, and step count.

A simple questionnaire of acceptance of playing TG and PE lesson activities was developed based on Wasowicz
[45] and Zeng, Hipscher [46]. The questionnaire has five items on TG and five items on PE lesson activities, where the questions consist of enjoyment ( 2 items), satisfaction (2 items), suitability of activities (4 items), and future participation (2 items). A five-point Likert scale was used to represent the score, i.e., 1 (strongly disagree), 2 (disagree), 3 (neutral), 4 (agree), and 5 (strongly agree). The scores of the questionnaire range from 5 to 25 . A higher score indicates better acceptance towards playing TG and doing PE lesson activities. This questionnaire was pre-tested among a pilot sample of secondary school students for clarity, understanding, and language of each item before administering it into the study. The internal consistency of the questionnaire was 0.70 .

Statistical Analysis

IBM SPSS Statistics version 23 software was used to analyse all the data. Descriptive analysis (frequencies, percentages, means \pm standard deviations) was used to report demographic, anthropometric, PA data, and acceptance score on TG-PE and free-play PE lessons. Paired t-test was used to compare (1) PA variables during the TG-PE lesson and free-play PE lesson and (2) acceptance scores between TG and PE lesson activities. Independent t-test was used to test the difference of PA variables and acceptance scores between genders. P value of less than 0.05 was considered statistically significant.

\section{Results}

\section{Demographic Data}

A total of 56 students from Form $1(\mathrm{n}=27)$ and Form $2(\mathrm{n}=29)$ were involved in this study. Subjects' mean age was $13.5 \pm 0.5$ years. Most of the students were boys $(57 \% ; n=32)$ and the rest were girls $(43 \% ; n=24)$. The majority race of the subjects were Malays $(96 \% ; n=54)$, followed by Chinese $(2 \% ; n=1)$, and others $(2 \% ; n=1)$.

\section{Anthropometric Data}

Table 1 shows anthropometric and body composition data of subjects. Subjects' weight, height, waist

Table 1. Subject's anthropometric and Body Composition [Mean \pm SD/ \% (n)]

\begin{tabular}{|c|c|c|c|}
\hline Parameters & Overall $(n=56)$ & Boys $(n=32)$ & Girls $(n=24)$ \\
\hline Weight (kg) & $53.9 \pm 16.4$ & $57.7 \pm 18.8$ & $48.9 \pm 11.2$ \\
\hline Height (cm) & $155.9 \pm 8.9$ & $159.4 \pm 9.3$ & $151.1 \pm 5.5$ \\
\hline Waist circumference $(\mathrm{cm})$ & $68.1 \pm 13.1$ & $72.3 \pm 13.9$ & $62.6 \pm 10.0$ \\
\hline BMI (kg/m²) & $21.8 \pm 4.9$ & $22.2 \pm 5.3$ & $21.3 \pm 4.4$ \\
\hline BMI-for-age (z-score) & $0.6 \pm 1.6$ & $0.7 \pm 1.7$ & $0.4 \pm 1.3$ \\
\hline Body fat percentage (\%) & $25.0 \pm 6.6$ & $23.2 \pm 6.2$ & $27.4 \pm 6.4$ \\
\hline \multicolumn{4}{|l|}{ BMI-for-age (z-score) categories ${ }^{a}$} \\
\hline - Normal (<2 SD) & $52(29)$ & $44(14)$ & $62(15)$ \\
\hline - Overweight (2 - 3 SD) & $21(15)$ & $22(7)$ & $21(5)$ \\
\hline - Obese (> 3 SD) & $27(15)$ & $34(11)$ & $17(4)$ \\
\hline \multicolumn{4}{|l|}{ Waist circumference categories ${ }^{b}$} \\
\hline - Not risk abdominal obesity (< 90 percentiles) & $92(47)$ & $78(25)$ & $92(22)$ \\
\hline - Abdominal obesity ( $\geq 90$ percentiles) & $8(9)$ & $22(7)$ & $8(2)$ \\
\hline
\end{tabular}

a WHO 2017 [41]; b Poh et al. 2011 [42] 
circumference, BMI-for-age z-score, and body fat percentage were $53.9 \pm 16.4 \mathrm{~kg}, 155.9 \pm 8.9 \mathrm{~cm}, 68.1 \pm$ $13.2 \mathrm{~cm}, 0.6 \pm 1.6$, and $25.0 \pm 6.6 \%$ respectively. Half of the subjects were categorised within normal BMI (52\%) whilst the rest were overweight (21\%) and obese (27\%). There were more obese boys (34\%) compared to obese girls $(17 \%)$. Only $8 \%$ of the subjects fell into abdominal obesity category.

Overall Physical Activity Data

Table 2 shows the comparison of PA variables between free-play and TG-PE lessons. Total activity count showed a significant $20 \%$ increase during TG-PE lesson (113832 \pm 32075 ) compared to free-play PE lesson (90662 \pm 55042; $\mathrm{p}=0.007)$. Time spent in MVPA during TG-PE lesson $(28.9 \pm 6.3 \mathrm{~min})$ was $19 \%$ higher than in free-play PE lesson $(23.5 \pm 12.8$ min; $p=0.006)$. Time spent in sedentary activity was reduced to as much as $45 \%$ during TG-PE lesson $(5.3 \pm 4.3 \mathrm{~min})$ compared to free-play PE lesson $(10.7 \pm 11.7 \mathrm{~min} ; \mathrm{p}=0.003)$. Step count was $23 \%$ higher during TG-PE lesson $(1379 \pm 455)$ than in freeplay PE lesson $(1066 \pm 890 ; \mathrm{p}=0.010)$.

Comparison of Physical Activity between Genders

Table 3 shows the gender comparison for PA variables between free-play and TG-PE lessons. Boys recorded a significantly higher step count $(1287 \pm 1023$ steps $)$ compared to girls $(772 \pm 570$ steps; $p=0.031)$ during the free-play PE lesson. However, there were no significant differences for the time spent in sedentary, time spent in MVPA, and total activity count between boys and girls during the same lesson. On the other hand, total activity count (boys: $126585 \pm 30966$; girls: $96829 \pm 25293$; $p=$ 0.000 ), time spent in MVPA (boys: $30.9 \pm 5.6 \mathrm{~min}$; girls: $26.2 \pm 6.2 \mathrm{~min} ; \mathrm{p}=0.004$ ), and step count (boys: 1563 \pm 472 steps; girls: $1134 \pm 290$ steps; $p=0.000$ ) were significantly greater in boys compared to girls during TGPE lesson.

Within the boys' group, the total activity count $(21 \% ; p=0.018)$ and time spent in MVPA $(19 \% ; p=$ 0.012 ) showed significant increases. While time spent in sedentary decreased significantly $(-48 \% ; \mathrm{p}=0.021)$ during TG-PE lesson compared to free-play PE lesson. Within the girls' group, the time spent in sedentary decreased significantly $(-52 \% ; \mathrm{p}=0.041)$ while the step count showed a significant increase $(32 \% ; \mathrm{p}=0.006)$ during TG-PE lesson compared to free-play PE lesson.

Comparison of Acceptance Score towards PE Lessons

Table 4 shows the comparison of overall and by domain acceptance scores towards playing TG-PE lesson and free-play PE lesson. Overall, subjects recorded higher acceptance scores for TG-PE lesson (19.29 \pm 4.21$)$

Table 2. Comparison of Physical Activity Variables between Free-Play PE Lesson and TG-PE Lesson (Mean \pm SD)

\begin{tabular}{llll}
\hline PA Variables & Free-play PE Lesson & TG-PE Lesson & p value \\
\hline Total activity counts & $90662 \pm 55042$ & $113832 \pm 32075^{*}$ & 0.007 \\
Time spent in MVPA (minutes) & $23.5 \pm 12.8$ & $28.9 \pm 6.3^{*}$ & 0.006 \\
Time spent in sedentary (minutes) & $10.7 \pm 11.7$ & $5.3 \pm 4.3^{*}$ & 0.003 \\
Step count & $1066 \pm 890$ & $1379 \pm 455^{*}$ & 0.010 \\
\hline
\end{tabular}

*significant difference between free-play PE lesson and TG-PE lesson

Table 3. Gender Comparison for Physical Activity Variables between Free-Play PE Lesson and TG-PE Lesson (Mean \pm SD)

\begin{tabular}{lll}
\hline PA Variables & Free-play PE Lesson & TG-PE Lesson \\
\hline $\begin{array}{l}\text { Total activity counts } \\
\text { Boys }(n=32)\end{array}$ & $99666 \pm 54587$ & $126585 \pm 30966^{\mathrm{a}, \mathrm{b}}$ \\
Girls $(\mathrm{n}=24)$ & $78657 \pm 54456$ & $96829 \pm 25293$ \\
Time spent in MVPA (minutes) & & \\
Boys ( $\mathrm{n}=32)$ & $25.0 \pm 11.5$ & $30.9 \pm 5.6^{\mathrm{a}, \mathrm{b}}$ \\
Girls $(\mathrm{n}=24)$ & $21.5 \pm 14.2$ & $26.2 \pm 6.2$ \\
Time spent in sedentary (minutes) & & \\
Boys ( $\mathrm{n}=32)$ & $8.4 \pm 9.1$ & $4.4 \pm 3.7^{\mathrm{b}}$ \\
Girls $(\mathrm{n}=24)$ & $13.7 \pm 14.1$ & $6.6 \pm 4.8^{\mathrm{b}}$ \\
Step count & & $1563 \pm 472^{\mathrm{a}}$ \\
Boys $(\mathrm{n}=32)$ & $1287 \pm 1023^{\mathrm{a}}$ & $1134 \pm 290^{\mathrm{b}}$ \\
Girls $(\mathrm{n}=24)$ & $772 \pm 570$ & \\
\hline
\end{tabular}

a significant comparison between gender within the same PE lesson; ${ }^{b}$ significant comparison between PE lessons within the same gender 
compared to free-play PE lesson $(17.59 \pm 3.13 ; \mathrm{p}=0.009)$. Domain of enjoyment scores for TG-PE lesson (4.0 \pm 1.0$)$ were significantly higher than free-play PE lesson (3.8 $\pm 1.1 ; \mathrm{p}=0.033)$. Scores for domain of satisfaction for TG-PE lesson $(7.6 \pm 1.9)$ were significantly higher than free-play PE lesson $(7.0 \pm 1.5 ; p=0.002)$. Meanwhile, for suitability and future participation domains, no difference was noted between TG-PE and free-play PE lessons.

Comparison of Acceptance Score towards PE Lessons across Gender

Table 5 shows the comparison of acceptance scores towards free-play PE lesson and TG-PE lesson across gender. Overall acceptance scores for TG-PE lesson were higher (boys: $18.66 \pm 4.78$; girls: $20.13 \pm 3.22$ ) compared to free-play PE lesson (boys: $17.00 \pm 3.17$; girls: $18.38 \pm$ $2.95)$ in both genders but were not statistically significant $(\mathrm{p}=0.089)$. Within the girls' group, acceptance scores towards TG-PE $(20.1 \pm 3.2)$ were significantly higher than free-play PE lesson $(18.4 \pm 3.0 ; \mathrm{p}=0.036)$.

For the acceptance scores based on domains across gender, only satisfaction in TG-PE lesson showed a

Table 4. Comparison of Acceptance Score towards Free-Play PE lesson and TG-PE Lesson (Mean \pm SD)

\begin{tabular}{llll}
\hline Score & Free-Play PE Lesson & TG-PE Lesson & p value \\
\hline Overall & $17.6 \pm 3.1$ & $19.3 \pm 4.2^{*}$ & 0.009 \\
By domain & & & 0.033 \\
- Enjoyment & $3.8 \pm 1.1$ & $4.0 \pm 1.0^{*}$ & 0.002 \\
- Satisfaction & $7.0 \pm 1.5$ & $7.6 \pm 1.9 *$ & 0.059 \\
- Suitability & $3.4 \pm 1.3$ & $3.9 \pm 1.2$ & 0.263 \\
- Future participation & $3.4 \pm 1.0$ & $3.7 \pm 1.1$ & \\
\hline
\end{tabular}

*Significant difference $(p<0.05)$ of score between PE lesson

Table 5. Comparison of Acceptance Score towards Free-Play PE Lesson and TG-PE Lesson across Gender (Mean \pm SD)

\begin{tabular}{lll}
\hline Score & Free-Play PE Lesson & TG-PE Lesson \\
\hline Overall & & \\
Boys $(n=32)$ & $17.0 \pm 3.2$ & $18.7 \pm 4.78$ \\
Girls $(n=24)$ & $18.4 \pm 3.0$ & $20.1 \pm 3.2^{\mathrm{a}}$ \\
By domain & & \\
- Enjoyment & & \\
Boys ( $n=32)$ & $3.8 \pm 1.2$ & $4.0 \pm 1.1$ \\
Girls $(n=24)$ & $3.8 \pm 1.0$ & $4.1 \pm 0.9$ \\
- Satisfaction & & \\
Boys ( $n=32)$ & $6.8 \pm 1.6$ & $7.3 \pm 2.1$ \\
Girls $(n=24)$ & $7.3 \pm 1.3$ & $8.1 \pm 1.5^{\mathrm{b}}$ \\
- Suitability & & $3.8 \pm 1.4$ \\
Boys $(n=32)$ & $3.2 \pm 1.3$ & $4.0 \pm 0.9$ \\
Girls $(n=24)$ & $3.8 \pm 1.3$ & \\
- Future participation & & $3.7 \pm 1.3$ \\
Boys ( $n=32)$ & $3.3 \pm 1.1$ & $3.8 \pm 0.9$ \\
Girls $(n=24)$ & $3.5 \pm 0.9$ & \\
\hline
\end{tabular}

a Significant difference $(p<0.05)$ of overall score between PE lesson within same gender; ${ }^{b}$ Significant difference $(p<0.05)$ of domain score between PE lesson within same gender 
sporty, who normally represent more than half of a class population [47]. The purpose of playing TG is more on promoting enjoyment rather than competition [48].

Our findings also demonstrated that playing TG does not only increase PAs in general, but also MVPAs. It is recommended that students engage in MVPA for at least $50 \%$ of the time they spend in PE class, one of the most critical outcome measures in determining the quality of a PE program [49], consistent with the evidence pointing to the association of MVPA with physical fitness and mental health [50]. The mean time spent in MVPA in the TG-PE lesson was $56 \%$ of the lesson time, indicating that TG can be a strategy to achieve MVPA of at least $50 \%$ of the lesson time. Fairclough and Stratton [51] had demonstrated that team games promote the highest levels of MVPA compared to individual activities and games. This could be explained in that team games are perceived to be fun and cooperative, and students can easily engage in PAs that require less specific skills, as in the case with TG [52]. In addition, the time spent in sedentary activity in this study was reduced to as much as $45 \%$ while playing TG compared to free-play $\mathrm{PE}$ lesson. In the current education systems, students spend about $97 \%$ of their time in school sitting in a traditional classroom setting [53]. Therefore, PE is considered as a predominant method to promote MVPA and reduce sedentariness during school hours [54]. In fact, Chen, Kim [11] in his study demonstrated the increase in daily MVPAs or sedentary behaviour respectively, highlighting the importance of PE in accumulating MVPAs in youth's daily lives.

As expected, this study observed that boys were generally $25 \%$ more active compared to girls, and boys also spent a greater proportion $(18 \%)$ of lesson time involved in MVPA during TG-PE lesson compared to girls. This finding is consistent with many previous studies [55-57] that recognise gender differences with regards to PA participation. Boys are generally more concerned with sports and team-based activities, as well as possessing competitive streaks, while girls are more engaged in individual activities such as dance, gymnastics, and swimming [51, 58]. It is also apparent that the nature of the TG employed in this study required substantial amount of whole body movement of differing speeds, thus it is likely that the girls were less motivated than the boys to physically exert themselves. According to Telford, Telford [59], the gap of PA between gender could also be explained by girls being less favourably influenced by socio-ecological factors at individual, family, school, and environmental levels. Meanwhile, MVPA did not differ between TG-PE and free-play PE lessons, suggesting that playing TG may provide a boost for PA among school girls.

The secondary aim of this preliminary study is to determine and compare acceptance between PE lesson incorporated with TG (TG-PE) and free-play PE lesson. Our findings showed that TG-PE lesson was preferred over free-play PE lesson. It is possible that TG were accepted due to these activities being less strenuous, fun, and more enjoyable $[24,43]$. Based on the acceptance by domains, subjects recorded higher enjoyment and satisfaction towards playing TG than free-play PE activities. The enjoyment and satisfaction levels increased due to the new activities being conducted during the $\mathrm{PE}$ lesson, which differed from the usual sports activities (e.g., football and badminton) [60]. Usual sports activities may be challenging and need more athletic skills which may not appeal to students who are less sports-oriented, i.e., half of class population [47]. McCarthy and Jones [61] also justified that there is no enjoyment when rules that are over-competitive, less socially-interactive, and less autonomous are enforced during sports activities.

Our findings also demonstrated that girls were satisfied towards playing TG over free-play PE activities compared to boys. Bronikowska, Petrovic [62] justified that girls enjoy traditional games due to those requiring less specific skills and less competition, while encouraging them to move at their own pace when playing. They also feel more enjoyable and conceive positive emotions when playing traditional games [48]. Compared to boys, girls are generally less concerned about sports activities that possess competitive streaks [51, 58]. Okely, Lubans [63] pointed out that adolescent girls are keener to play in a shorter duration, with frequent changes in the type of games, and prefer to play amongst them. Those reasons fit with this study protocol where the games were changed from one kind to another, played within 20 minutes, and played amongst girls only.

Playing TG is an excellent option in lieu of free-play PE lessons which are commonly practised in schools. When students are at liberty of carrying out their own PA, this can lead to issues such as students spending little effort during PE lessons [64], or avoiding participation altogether [65], especially when supervision is minimal. The strength of this present study shows incorporating TG during PE lessons requires minimal equipment and space than organised sports. As for the PE teachers, teaching TG during PE lessons can be convenient, requires less specific skills to teach, and relevant to incorporate into PE curriculum.

\section{Limitations and Recommendations}

However, this study has several limitations. We did not manage to determine the PA variables for each game separately. Although the types of TG (i.e. Galah Panjang [Long Pole] and Baling Selipar [Throwing Slipper]) chosen for this study were effective at increasing PAs during PE lesson. Therefore, we could not determine which traditional game was more advantageous than the other in regards to promoting MVPA, if such difference exists. This certainly highlights the need for such studies in the future. Second, the sample size for this study was relatively small due to time constraints. But we felt it is sufficient to provide the baseline information needed for planning future intervention involving TG in a bigger scale among school students. Third, even though the comparison of playing TG during PE lesson was made against free-play PE lesson, we only managed to conduct 
one session in both PE lessons due to time constraints. We suggested further investigation for longer duration to compare the acceptance scores between TG and PE lessons for a better picture.

\section{Conclusion}

Our findings showed that playing TG can increase PAs among secondary school students. Playing TG was preferred during PE lesson over free-play PE lesson especially among girls. This comparison study showed that incorporating fun and enjoyable activities such as TG during PE lessons can be an alternative in promoting PA during school hours. Future studies should expand into examining which other types of games that are more attractive and appealing to boost PAs in this particular group.

\section{Highlights}

Playing TG can an excellent option for improving PA levels during free-play PE lesson among secondary school students.

\section{Acknowledgements}

We would like to acknowledge all the students who took part in the study, the school principal and teachers of the school involved.
1. Hills AP, Andersen LB, Byrne NM. Physical activity and obesity in children. British Journal of Sports Medicine. 2011;45(11):866-70. https://doi.org/10.1136/bjsports-2011-090199

2. Tremblay MS, Barnes JD, González SA, Katzmarzyk PT, Onywera VO, Reilly JJ, et al. Global Matrix 2.0: report card grades on the physical activity of children and youth comparing 38 countries. Journal of Physical Activity and Health. 2016;13(11 Suppl 2):S343-S66. https://doi.org/10.1123/jpah.2016-0594

3. Baharudin A, Zainuddin AA, Manickam MA, Ambak R, Ahmad MH, Naidu BM, et al. Factors associated with physical inactivity among school-going adolescents: data from the Malaysian School-Based Nutrition Survey 2012. Asia Pacific Journal of Public Health. 2014;26(5_suppl):27S-35S. https://doi.org/10.1177/1010539514543682

4. IKU. National Health and Morbidity Survey 2017: Adolescent Nutrition Survey 2017, Malaysia. Kuala Lumpur: Institut Kesihatan Umum, 2017. [cited 2020 June 23]. Available from: http://iku.moh.gov.my/nhms-2017

5. Lee WASS, Rengasamy S, Hooi LB. The level of intrinsic motivation among 13,14 and 16 years old school students in physical education lessons. Asian Journal of Physical Education and Computer Science in Sports. 2015;12(1):116121.

6. Johnson TG, Turner L. The physical activity movement and the definition of physical education. Journal of Physical Education, Recreation \& Dance. 2016;87(4):8-10. https://doi.org/10.1080/07303084.2016.1142192

7. Ardoy DN, Fernández-Rodríguez J, Jiménez-Pavón D, Castillo R, Ruiz J, Ortega F. A Physical education trial improves adolescents' cognitive performance and academic achievement: the EDUFIT study. Scandinavian Journal of Medicine \& Science in Sports. 2014;24(1):e52-e61. https://doi.org/10.1111/sms.12093

8. Telford RD, Cunningham RB, Fitzgerald R, Olive LS, Prosser L, Jiang $\mathrm{X}$, et al. Physical education, obesity, and academic achievement: a 2-year longitudinal investigation of Australian elementary school children. American Journal of Public Health. 2012;102(2):368-74. https://doi.org/10.2105/AJPH.2011.300220

9. Rasberry CN, Lee SM, Robin L, Laris B, Russell LA, Coyle KK, et al. The association between schoolbased physical activity, including physical education, and academic performance: a systematic review of the literature. Preventive Medicine. 2011;52:S10-S20. https://doi.org/10.1016/j.ypmed.2011.01.027

10.Cowley J, Kiely J, Collins D. Is there a link between self-perceived stress and physical activity levels in Scottish adolescents? International Journal of Adolescent Medicine and Health. 2019;31:20160104. https://doi.org/10.1515/ijamh-2016-0104

11.Chen S, Kim Y, Gao Z. The contributing role of physical education in youth's daily physical activity and sedentary behavior. BMC Public Health. 2014;14(1):110. https://doi.org/10.1186/1471-2458-14-110

12.Silva DAS, Chaput J-P, Katzmarzyk PT, Fogelholm M, $\mathrm{Hu}$ G, Maher C, et al. Physical education classes, physical activity, and sedentary behavior in children. Medicine \& Science in Sports \& Exercise. 2018;50(5):995-1004. https://doi.org/10.1249/MSS.0000000000001524

13.Wee EH. Contemporary issues in the teaching of PE in Malaysia: Proceedings of the $9^{\text {th }}$ International Sports Science Conference 2012 June 25-28; Kelantan, Malaysia: USM; 2013. P. 120-127.

14.Ismail WAW, Muhamad TA, Hubungan faktor penghalang terhadap penglibatan pelajar dalam Pendidikan Jasmani di sekolah menengah [The relationship of barriers to student involvemet in physical education in secondary schools]. Proceedings of the 1st International Conference on Language, Education and Innovation 2015 Mar 16-17; Kuala Lumpur, Malaysia: Infobase Creation; 2015. P. 123-130. (in Malay)

15.Kilue D, Muhamad TA. Cabaran pengajaran subjek pendidikan jasmani di sekolah menengah di Malaysia [Challenges in the teaching of physical education subject in Malaysian secondary schools]. Journal of Nusantara Studies (JONUS). 2017;2(2):53-65. (In Malay) https://doi.org/10.24200/jonus.vol2iss2pp53-65

16.Husain MZ, Hasan A, Wahab NBA, Jantan J. Determining teaching effectiveness for physical education teacher. Procedia-Social and Behavioral Sciences. 2015;172:733-40. https://doi.org/10.1016/j.sbspro.2015.01.426

17.MorganP,BourkeS.Non-specialistteachers'confidencetoteach PE: the nature and influence of personal school experiences in PE.PhysicalEducationandSportPedagogy.2008;13(1):1-29. https://doi.org/10.1080/17408980701345550

18. Rustam S, Kassim M. The direction of physical and health education in 21 st century in Malaysia. Advances in Natural and Applied Sciences. 2018 [cited 2020 July 29];12(4):11-6. Available from:http:/www.aensiweb.net/AENSIWEB/anas/ anas/2018/April/11-15(3).PDF

19.Zahidi M, Samad R. Influence of school environment in the teaching and learning of physical education. Turkish Journal of Sport and Exercise. 2014;16(2):70-6. https://doi.org/10.15314/tjse.79065

20.Ali SKS, Zahidi MA, Samad RSA, Wee A. Faktor kekangan ibu bapa dan persekitaran sekolah dalam pelaksanaan 
pengajaran pendidikan jasmani di sekolah rendah [Parental constraints and school environment factors in the implementation of Physical Education in primary school]. The Asia Pacific Journal of Curriculum and Teaching (JuKu). 2017 [cited 2020 June 23];2(2):1-15. (In Malay). Available from: https://juku.um.edu.my/article/view/8066

21.Abu Bakar NFS, Penglibatan pelajar dalam aktiviti pendidikan jasmani di sekolah menengah sekitar daerah Sentul, Kuala Lumpur [Student involvement in physical education activities in secondary schools around Sentul district, Kuala Lumpur], Kuala Lumpur. Proceedings of the International Seminar in Education Issues (ISPEN 2018); 20185 July; Selangor, Malaysia: KUIS; 2018. P. 45-51. (In Malay)

22.Burns RD, Fu Y, Podlog LW. School-based physical activity interventions and physical activity enjoyment: A meta-analysis. Preventive medicine. 2017;103:84-90. https://doi.org/10.1016/j.ypmed.2017.08.011

23.Visek AJ, Achrati SM, Mannix HM, McDonnell K, Harris BS, DiPietro L. The fun integration theory: toward sustaining children and adolescents sport participation. Journal of Physical Activity and Health. 2015;12(3):424-33. https://doi.org/10.1123/jpah.2013-0180

24.Tangkudung J, Aini K, Puspitorini W. Development of Physical Fitness Materials based on Traditional Games for Junior High School. Proceedings of the 1st International Conference on Innovation in Education (ICoIE 2018), Padang, Indonesia: Atlantis Press; 2019. https://doi.org/10.2991/icoie-18.2019.91

25.Zulkifli M, Putra A, Yusof M, Anuwar S, Norzaman NZA, Razali AF. Re-creation of Malaysian traditional game namely 'Baling Selipar': A Critical Review. International Journal of Science, Environment and Technology. [cited 2020 June 23] 2014;3(6):2084-9. Available from: http://www.ijset.net/ journal/451.pdf

26.Louth S, Jamieson-Proctor R. Inclusion and engagement through traditional Indigenous games: enhancing physical self-efficacy. International Journal of Inclusive Education. 2018:1-15. https://doi.org/10.1080/13603116.2018.1444799

27.Rahman ISA. Inventory of ASEAN Traditional Games and Sports. Culture ACo, ASEAN Committee on Culture and Information; 1998.

28.Charles MAG, Abdullah MR, Musa RM, Kosni NA. The effectiveness of traditional games intervention program in the improvement of form one school-age children's motor skills related performance components. Journal of Physical Education and Sport. 2017;17:925-30. https://doi.org/10.7752/jpes.2017.s3141

29.Khan MZ, Abbas SG, Zeb R. The reasons for traditional games losing popularity: A case study of Skhy (Calf) in Nihagdara, KP (Pakistan). THE SPARK A HEC Recognized Journal. 2018 [cited 2020 Aug 23];3(1):100-11. Available from: http://journal.suit.edu.pk/index.php/spark/article/ view/484/445

30.Ali SKS, Ranjbar Z. The effect of traditional games intervention on overweight among secondary school students in Iran. Advanced Science Letters. 2018;24(7):5434-7. https://doi.org/10.1166/asl.2018.11751

31.Abdullah B, Amri S, Yee KL, Samah BA. The impact of traditional games on the gross motor skill development of an early childhood. The Social Sciences. 2013;8(6):590-5. https://doi.org/10.3923/sscience.2013.590.595

32.Zahari ZA, Desa MAM, Bakhir NM. Permainan tradisional dan teknologi: Penelitian dan tinjauan terhadap persepsi kanak-kanak [Traditional games and technology: A review of children's perceptions]: Proceedings of the 1st International Conference On Creative Media, Design \& Technology (REKA2014); Penang, Malaysia: USM; 2014. P.67-72. (In Malay)

33.Valentine G, McKendrck J. Children's outdoor play: Exploring parental concerns about children's safety and the changing nature of childhood. Geoforum. 1997;28(2):219-35. https://doi.org/10.1016/S0016-7185(97)00010-9

34.Booc RP, Rafaela KB, Torres MJ, Bulawan RP, II LCJ, Cortuna IJM, Ascunsion JE. The traditional Filipino games: status check among generation z. ISJ Theoretical \& Applied Science, 10 (78). 2019:150-2. https://doi.org/10.15863/TAS

35.Bashir J, Zain-Ul-Wahab BA. Polyhedron analysis of traditional games of Khyber Pakhtunkhwa, Pakistan. WALIA Journal. 2018 [cited 2020 July 29];32(1):5. Availbale from: http://waliaj.com/wp-content/2018/Issue $\% 201, \% 20$ 2018/22w.pdf

36. Mohd Yusoff MY. Permainan tradisional masyarakat Melayu dalam kalangan generasi $\mathrm{Z}$ [Malay traditional games among generation Z]. Proceeding of the 7th International Conference on Social Sciences and Humanities 2018 1213 Nov; Selangor, Malaysia: UKM; 2018. P. 123-131. (In Malay)

37.Trajkovik V, Malinovski T, Vasileva-Stojanovska T, Vasileva M. Traditional games in elementary school: Relationships of student's personality traits, motivation and experience with learning outcomes. PloS One. 2018;13(8):e0202172. https://doi.org/10.1371/journal.pone.0202172

38.Rothlein L, Einspruch E, Goldberg S. A study of traditional circle games played in public school kindergartens across the United States. International Journal of Early Childhood. 1988;20(2):55. https://doi.org/10.1007/BF03174563

39.Faul F, Erdfelder E, Lang A-G, Buchner A. G* Power 3: A flexible statistical power analysis program for the social, behavioral, and biomedical sciences. Behavior Research Methods. 2007;39(2):175-91. https://doi.org/10.3758/BF03193146

40.Wilson DK, Evans AE, Williams J, Mixon G, Sirard JR, Pate R. A preliminary test of a student-centered intervention on increasing physical activity in underserved adolescents. Annals of Behavioral Medicine. 2005;30(2):119. https://doi.org/10.1207/s15324796abm3002_4

41.WHO. Growth reference data for 5-19 years [document on the Internet] WHO 2007 [cited 201731 Oct]. Available from:http://www.who.int/growthref/en/

42.Poh BK, Jannah AN, Chong LK, Ruzita AT, Ismail M, McCarthy D. Waist circumference percentile curves for Malaysian children and adolescents aged 6.016.9 years. Pediatric Obesity. 2011;6(3-4):229-35. https://doi.org/10.3109/17477166.2011.583658

43.Ahmad S, Zakaria S. Permainan tradisional di Malaysia [Traditional games in Malaysia]. Kuala Lumpur: Buku Must; 2008. (In Malay)

44.Freedson P, Pober D, Janz FK. Calibration of accelerometer output for children. Med Sci Sports Exerc. 2005;37:S523-S30. https://doi.org/10.1249/01.mss.0000185658.28284.ba

45.Wasowicz I. Traditional Games Comenius Project 2010 [document on the Internet] Comenius Project 2010 [cited 2018 $4 \mathrm{Feb}$. Available from: http://www.traditionalgamesandtoys. com/page 10.html\&as_qdr=y15

46.Zeng HZ, Hipscher M, Leung RW. Attitudes of high school students toward physical education and their sport activity preferences. Journal of Social Sciences. 2011;7(4):529. https://doi.org/10.3844/jssp.2011.529.537 
47.Owen MB, Curry WB, Kerner C, Newson L, Fairclough SJ. The effectiveness of school-based physical activity interventions for adolescent girls: A systematic review and meta-analysis. Preventive Medicine. 2017;105:237-49. https://doi.org/10.1016/j.ypmed.2017.09.018

48.Lavega P, Alonso JI, Etxebeste J, Lagardera F, March J. Relationship between traditional games and the intensity of emotions experienced by participants. Research Quarterly for Exercise and Sport. 2014;85(4):457-67. https://doi.org/10.1080/02701367.2014.961048

49.Hollis JL, Sutherland R, Williams AJ, Campbell E, Nathan $\mathrm{N}$, Wolfenden $\mathrm{L}$, et al. A systematic review and meta-analysis of moderate-to-vigorous physical activity levels in secondary school physical education lessons. International Journal of Behavioral Nutrition and Physical Activity. 2017;14(1):52. https://doi.org/10.1186/s12966-017-0504-0

50.Poitras VJ, Gray CE, Borghese MM, Carson V, Chaput J-P, Janssen I, et al. Systematic review of the relationships between objectively measured physical activity and health indicators in school-aged children and youth. Applied Physiology, Nutrition, and Metabolism. 2016;41(6):S197-S239. https://doi.org/10.1139/apnm-2015-0663

51.Fairclough S, Stratton G. 'Physical education makes you fit and healthy'. Physical education's contribution to young people's physical activity levels. Health Education Research. 2004;20(1):14-23. https://doi.org/10.1093/her/cyg101

52.Zhou Y, Wang L. Correlates of physical activity of students in secondary school physical education: A systematic review of literature. BioMed Research International. 2019;2019. https://doi.org/10.1155/2019/4563484

53.Cardon G, De Clercq D, De Bourdeaudhuij I, Breithecker D. Sitting habits in elementary schoolchildren: a traditional versus a "Moving school". Patient Education and Counseling. 2004;54(2):133-42. https://doi.org/10.1016/S0738-3991(03)00215-5

54.Fairclough S, Stratton G. Physical activity levels in middle and high school physical education: a review. Pediatric Exercise Science. 2005;17(3):217-36. https://doi.org/10.1123/pes.17.3.217

55.Smith NJ, Lounsbery MA, McKenzie TL. Physical activity in high school physical education: impact of lesson context and class gender composition. Journal of Physical Activity and Health. 2014;11(1):127-35. https://doi.org/10.1123/jpah.2011-0334

56.Teo PS, Nurul-Fadhilah A, Aziz ME, Hills AP, Foo LH. Lifestyle practices and obesity in Malaysian adolescents. International Journal of Environmental Research and
Public Health. 2014;11(6):5828-38. https://doi.org/10.3390/ ijerph110605828

57.Cheah YK, Lim HK, Kee CC, Ghazali SM. Factors associated with participation in physical activity among adolescents in Malaysia. International Journal of Adolescent Medicine and Health. 2016;28(4):419-27. https://doi.org/10.1515/ijamh-2015-0030

58. Marques A, Ekelund U, Sardinha LB. Associations between organized sports participation and objectively measured physical activity, sedentary time and weight status in youth. Journal of Science and Medicine in Sport. 2016;19(2):154-7. https://doi.org/10.1016/j.jsams.2015.02.007

59. Telford RM, Telford RD, Olive LS, Cochrane T, Davey R. Why are girls less physically active than boys? Findings from the LOOK longitudinal study. PloS One. 2016;11(3):e0150041. https://doi.org/10.1371/journal.pone.0150041

60.Gao Z, Zhang P, Podlog LW. Examining elementary school children's level of enjoyment of traditional tag games vs. interactive dance games. Psychology, Health \& Medicine. 2014;19(5):605-13. https://doi.org/10.1080/13548506.2013.845304

61.McCarthy PJ, Jones MV. A qualitative study of sport enjoyment in the sampling years. The sport psychologist. 2007;21(4):400-16. https://doi.org/10.1123/tsp.21.4.400

62.Bronikowska M, Petrovic L, Horvath R, Hazelton L, Ojaniemi A, Alexandre J, et al. History and cultural Context of Traditional Sports and Games in Selected European Countries. In: Bronikowska M, Laurent JF, editors. Recall:Games of the Past-Sports for Today.Poland:TAFISA; 2015.

63. Okely AD, Lubans DR, Morgan PJ, Cotton W, Peralta L, Miller J, et al. Promoting physical activity among adolescent girls: the girls in sport group randomized trial. International Journal of Behavioral Nutrition and Physical Activity. 2017;14(1):81. https://doi.org/10.1186/s12966-017-0535-6

64.Ntoumanis N, Pensgaard A-M, Martin C, Pipe $\mathrm{K}$. An idiographic analysis of amotivation in compulsory school physical education. Journal of Sport and Exercise Psychology. 2004;26(2):197-214. https://doi.org/10.1123/jsep.26.2.197

65.Brooks F, Magnusson J. Taking part counts: adolescents' experiences of the transition from inactivity to active participation in school-based physical education. Health Education Research. 2006;21(6):872-83. https://doi.org/10.1093/her/cyl006 


\section{Information about the authors:}

‘Arif Azlan; https://orcid.org/0000-0002-6026-4169; p91912@siswa.ukm.edu.my; Nutritional Sciences Program \& Centre for Community Health Studies, Faculty of Health Science, National University of Malaysia; Kuala Lumpur, Malaysia.

Nadzirah Ismail; https://orcid.org/0000-0003-3019-5120; nadzirahismail01@gmail.com; Nutritional Sciences Program \& Centre for Community Health Studies, Faculty of Health Science, National University of Malaysia; Kuala Lumpur, Malaysia.

Nor Farah Mohamad Fauzi; https://orcid.org/0000-0003-0289-5795; norfarah@ukm.edu.my; Occupational Therapy Program \& Centre for Community Health Studies, Faculty of Health Science, National University of Malaysia; Kuala Lumpur, Malaysia.

Ruzita Abd. Talib; (Corresponding Author); https://orcid.org/0000-0002-3174-7065; rzt@ukm.edu.my; Nutritional Sciences Program \& Centre for Community Health Studies, Faculty of Health Science, National University of Malaysia; Kuala Lumpur, Malaysia.

Cite this article as:

Azlan 'A, Ismail N, Fauzi NFM, Talib RAbd.. Playing traditional games vs. free-play during physical education lesson to improve physical activity: a comparison study. Pedagogy of Physical Culture and Sports, 2021;25(3):178-187. https://doi.org/10.15561/26649837.2021.0306

This is an Open Access article distributed under the terms of the Creative Commons Attribution License, which permits unrestricted use, distribution, and reproduction in any medium, provided the original work is properly cited (http://creativecommons.org/licenses/by/4.0/deed.en).

Received: 10.11 .2020

Accepted: 22.01.2021; Published: 30.06.2021 